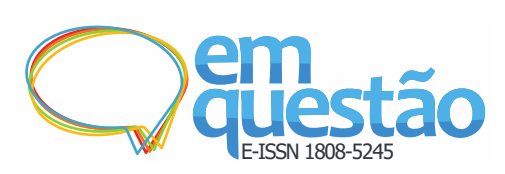

\title{
Museu da Vida e seus públicos: reflexões sobre a zona de influência e o papel social de um museu de ciência
}

\author{
Diego Vaz Bevilaqua \\ Doutor; Fundação Oswaldo Cruz, Rio de Janeiro, RJ, Brasil; \\ diego.bevilaqua@fiocruz.br \\ Ana Carolina de Souza Gonzalez \\ Doutoranda; Fundação Oswaldo Cruz, Rio de Janeiro, RJ, Brasil; \\ ana.gonzalez@fiocruz.br \\ Sonia Maria Figueira Mano \\ Doutora; Fundação Oswaldo Cruz, Rio de Janeiro, RJ, Brasil; \\ sonia.mano@fiocruz.br \\ Vanessa Fernandes Guimarães \\ Doutora; Fundação Oswaldo Cruz, Rio de Janeiro, RJ, Brasil; \\ vanesssa.guimaraes@ fiocruz.br \\ Wanessa da Silva de Almeida \\ Doutora; Fundação Oswaldo Cruz, Rio de Janeiro, RJ, Brasil; \\ wanessa.silva@icict.fiocruz.br
}

Resumo: Este artigo retrata o processo de definição da zona de influência do Museu da Vida, ou seja, das áreas do município do Rio de Janeiro de onde a maioria dos seus visitantes provém e cuja população é a base para a amostragem da pesquisa. Como resultados, este artigo faz uma análise sociodemográfica desse público e apresenta algumas de suas características relevantes. Essa definição de zona de influência, dentro da cidade do Rio de Janeiro, uniu conceitos de território e o conhecimento acumulado da proveniência dos visitantes do Museu da Vida. Definiu-se essa zona como uma área contínua do município do Rio de Janeiro que abrange Zona Central, Grande Tijuca, Zona Norte e Grande Jacarepaguá. Nesta zona de influência, 1.296 pessoas responderam a um questionário autoaplicado, das quais $13 \%$ já haviam visitado o Museu da Vida. Em contraste com aqueles que nunca visitaram o Museu, o público que já o visitou é relativamente jovem, com uma discreta maioria de mulheres e com renda bem distribuída de acordo com a demografia local, porém com um grau de escolaridade maior que a média. Analisaram-se, também, hábitos culturais relacionados à busca de informação em ciência e tecnologia na infância; a percepção dos visitantes sobre a influência da visita ao museu; seu interesse, conhecimento e engajamento a respeito de temas de ciência e tecnologia e a forma como os visitantes lidam com notícias falsas em ciência. Essas análises permitem uma visão mais sistêmica da importância de um museu de ciência em uma região com baixíssima oferta de equipamentos de ciência e cultura. 
Palavras-chaves: Estudo de público. Divulgação científica. Museu de ciência. Zona de influência. Museu da Vida.

\section{Introdução}

O papel da ciência e tecnologia e de seus frutos na sociedade contemporânea é inegável. Sua crescente presença tem moldado nossa cultura, revolucionando diversos setores da vida humana e influenciando diretamente os modelos produtivos; os modos e fluxos de comunicação; as oportunidades e formas de aprendizagem. Porém, o empreendimento científico e tecnológico, além de requerer elevados níveis de investimento, depende também de um constante aporte de mão de obra especializada. Estas características requerem uma maior participação da sociedade, não só nas decisões sobre o financiamento do sistema científico-tecnológico, como também em sua gestão e funcionamento. Embora não exista a possibilidade de um indivíduo dominar todos os aspectos de sua cultura, é importante que exista um mínimo de participação desse indivíduo nos processos culturais nos quais está inserido, de modo a permitir sua articulação com os demais membros da sociedade e seus modos de produção e subsistência (LEVY JUNIOR, 1952 ${ }^{1}$ apud LARAIA, 1986). Outra questão, igualmente importante, que se coloca neste contexto é o empoderamento do indivíduo para o exercício de uma cidadania esclarecida que possa contribuir para um controle social sobre o uso da ciência e de seus frutos.

A necessidade de atender a esta agenda estratégica deu origem a dois movimentos de natureza assimétrica, que em alguns casos se tornaram políticas públicas. O primeiro, que começou no início do século passado, visava a inserir o cidadão comum no contexto de sua cultura contemporânea científicotecnológica. Este movimento deu origem a diversos programas educativos e de popularização da ciência, especialmente em museus, e ganhou maior impulso por volta da década de 1970 nos recém-criados centros de ciência. Outro movimento, cujo enfoque é o reforço e a melhoria do ensino de ciências e da matemática nas escolas, visava a um melhor desempenho dos alunos nestas disciplinas, aferido pela participação em testes internacionais (PISA) ou por escalas próprias adotadas pelos respectivos países. O investimento no ensino 
formal foi considerado estratégico e foi enfatizado, partindo-se da ideia de que a escola é o local e o momento onde a aprendizagem ocorre.

No entanto, uma pesquisa abrangente realizada pelo Harvard Family Research Project (2007), nos Estados Unidos da América, concluiu que esta premissa não está correta. Quarenta anos de resultados acumulados de pesquisas demonstraram que o acesso às oportunidades complementares ou extraescolares de educação é um indicador melhor na previsão do sucesso no desenvolvimento, na aprendizagem e no desempenho escolar dos estudantes. A pesquisa também indica que crianças em situação de vulnerabilidade social e em desvantagem econômica têm menos acesso a essas oportunidades. Tal iniquidade prejudica significativamente sua formação e reduz suas chances de sucesso acadêmico. Estes dados sugerem que as experiências em educação não formal de ciências têm um papel fundamental em apoiar e facilitar a aprendizagem de ciências ao longo da vida.

Louise Archer e outros (2015) argumentam, usando o conceito de capital cultural de Bourdieu (1986), que o ambiente cultural de formação do indivíduo traz vantagens notáveis no desempenho escolar. Dessa forma, a parcela privilegiada da população - que culturalmente cresce com acesso a um capital científico e com possibilidades de desenvolver um capital científico seu a partir da leitura de textos de divulgação científica, de programas audiovisuais de conteúdo científico, da ida a museus de ciência e da participação em feiras de temas relacionados - vai apresentar uma maior vantagem educacional no campo das ciências. Além disso, o próprio ambiente científico é um espaço de convivência e participação no campo da ciência.

O objetivo não é diminuir a importância e o valor do processo formal de escolarização, mas sim avaliar se a escola deve continuar sendo vista como o único meio, ou como o meio mais importante e efetivo, para promover a compreensão e o interesse científico por parte do público (FALK; DIERKING, 2010). Embora haja um corpo crescente de dados apontando a importância da contribuição das experiências extraescolares informais ou de educação não formal para a compreensão pública da ciência, há uma necessidade de pesquisas mais abrangentes sobre o tema. Neste contexto os museus e centros de ciência 
destacam-se não só pelas oportunidades diferenciadas de aprendizagem num ambiente não formal, lúdico e motivador (FALK; STORKSDIECK, 2005; HEIN, 1998), mas também pelo compromisso com a qualidade, imparcialidade e fidedignidade dos conhecimentos/informações disponibilizados ao público.

Falk e colaboradores (2016) conduziram uma pesquisa internacional que foi aplicada originalmente em um consórcio de 13 países (Canadá, Colômbia, México, Estados Unidos, Finlândia, Reino Unido, Portugal, Bélgica, Suécia, Noruega, Taiwan, Singapura e Austrália) por 17 centros ou museus de ciência em uma amostra internacional que envolveu 13.558 jovens e adultos. Em função da natureza complexa e cumulativa da aprendizagem de ciência, foi adotada nesse estudo uma abordagem epidemiológica, pois, apesar de os resultados desse tipo não demonstrarem relações de causalidade, permitem ao pesquisador afirmar com um grau determinado de significância estatística se certos fatores contribuem ou não para um resultado. Os indicadores selecionados por esse consórcio para avaliação de impacto foram: (I) o conhecimento sobre ciências de adultos e jovens; (II) seus interesses e engajamento com a ciência (dentro e fora da escola); (III) a probabilidade de seguir carreira ou hobbies relacionados à ciência; (IV) a autoconfiança na sua competência para temas de ciência e tecnologia; (V) a criatividade e a capacidade de resolução de problemas. A conclusão encontrada é que, dentro do universo analisado, a visita de adultos ao museu ou ao centro de ciência correlacionou-se positivamente com as dimensões de impacto relacionadas aos indicadores (I), (II), (III) e (IV).

Os estudos de público de museus vêm emergindo como um campo de grande interesse para diretores e profissionais dessas instituições. Inúmeras pesquisas produziram dados relativos às experiências do visitante nas diferentes atividades do museu, em lugar de medir unicamente o êxito das exposições (HOOD, 1993). Estes estudos realizados pelos museus vêm buscando compreender as especificidades de um ambiente não formal de educação em suas várias ações dirigidas aos seus diferentes públicos. As audiências de museus, de modo geral, são constituídas de forma dinâmica e são compostas por segmentos sociais diferentes (ALMEIDA, 2005). A visita ao museu é percebida como uma experiência resultante dos contextos pessoal, social e físico dos 
visitantes (FALK; DIERKING, 2013), ancorada em regras e referências mais ou menos compartilhadas entre estes e curadores, cientistas e diferentes segmentos da sociedade e passíveis de negociação durante a situação observada. O significado desta prática se constrói na relação complexa entre diversos fatores, mas, por tratar-se de uma experiência de livre escolha do sujeito (FALK; DIERKING, 2010), a prática reveste-se de uma característica singular e pessoal.

A simples oferta cultural, porém, não basta para que o público compareça aos museus. Muitos não chegam a usufruir e de fato nem tentam, não se sentem convidados: são os não públicos da cultura. Esta situação, embora pareça fruto de uma livre escolha, determinada por uma questão de preferência pessoal, na verdade é induzida pela distribuição social do capital cultural, que permite distinguir as práticas e ofertas culturais, avaliá-las e usufruir delas (DAWSON, 2014; TRAUTMANN et al., 2018). A produção de conhecimento sobre as formas de apropriação dos museus pela sociedade é um requisito essencial para a avaliação, a orientação e o planejamento de políticas públicas não só no campo da cultura, mas também para as instituições comprometidas com o desenvolvimento científico e tecnológico.

O Museu da Vida - museu de ciência da Fundação Oswaldo Cruz completou 20 anos em 2019, tendo se tornado um dos principais museus de ciência do Brasil, com um público presencial de cerca de 4 milhões de pessoas em suas atividades e exposições intra e extramuros. A partir de estudos de monitoramento do público visitante, realizados tradicionalmente desde sua fundação, foi possível colocar em prática uma investigação que possibilitou desenhar um panorama mais abrangente das relações do Museu com a sociedade. Sabemos que $89 \%$ dos visitantes que vão até o Museu da Vida são provenientes da Zona Norte, Zona Oeste e da Baixada Fluminense e que apenas $2 \%$ são da Zona Sul da cidade (MANO et al., 2015), região com maior presença de equipamentos culturais. Diante destes dados, o número de visitantes do Museu da Vida impressiona pelo seu alcance como equipamento de inclusão cultural. Segundo pesquisa da Secretaria Municipal de Cultura do Rio de Janeiro, realizada em 2015 por JLeiva Cultura \& Esporte (2016) em parceria com o Instituto de Pesquisa DataFolha sobre hábitos culturais dos cariocas, os 
moradores das zonas Norte e Oeste do Rio apresentam os menores índices de frequência a museus e exposições de arte (25\% e $28 \%$, respectivamente). É também nas zonas Norte e Oeste que se concentram os maiores públicos considerados potenciais a serem incluídos (37\% e $28 \%$, respectivamente).

Nesse contexto, ao longo dos anos de 2017 e 2018, foi realizado um amplo levantamento junto à população das regiões mais próximas ao Museu da Vida, com o objetivo de conhecer a população da sua zona de influência e investigar que parte dela constitui seu público e quais são seus hábitos e interesses no campo da cultura científica.

\section{Metodologia}

A metodologia adotada nesta pesquisa consistiu numa adaptação do protocolo internacional desenvolvido por Falk e outros (2016) para a investigação do impacto social de um centro ou museu de ciência em suas comunidades de influência. Sua metodologia consiste em uma abordagem epidemiológica do problema, buscando avaliar correlações entre variáveis independentes e indicadores previamente construídos.

$\mathrm{Na}$ adaptação da metodologia para o caso brasileiro, optamos por apenas focar nos indicadores (I) o conhecimento sobre ciências de adultos e jovens; (II) seus interesses e engajamento com a ciência (dentro e fora da escola); (IV) a autoconfiança na sua competência para temas de ciência e tecnologia. A dimensão (III) a probabilidade de seguir carreira ou hobbies relacionados à ciência foi considerada fora das missões do Museu da Vida e o questionário original obteve resultados pouco satisfatórios para a dimensão (V) a criatividade e capacidade de resolução de problemas. Além disso, as questões foram adaptadas e contextualizadas localmente.

\subsection{Definição da zona de influência}

A zona de influência deve ser o território (SCHEINER, 2012) onde o museu se situa, um espaço contíguo, onde ele é um ator cultural de relevância. Nesse território, o museu deve engajar-se como um ator cultural que integra os 
públicos e seus discursos de forma múltipla e com o objetivo de reforçar a identidade da região.

A partir dos dados obtidos na rodada de 2013 do Observatório de Museus e Centros de Ciência e Tecnologia (MANO et al., 2015), foi realizado um levantamento dos bairros de residência dos visitantes espontâneos do Museu da Vida e suas respectivas Áreas de Planejamento (AP). A zona de influência foi então definida como o espaço geográfico da cidade do Rio de Janeiro, contíguo a essa instituição, de onde a procedência dos visitantes espontâneos foi superior ao peso demográfico das respectivas Áreas de Planejamento.

\subsection{Instrumento da pesquisa e amostra}

A metodologia baseou-se em um questionário autoaplicado com 29 perguntas fechadas e uma (1) aberta em amostras populacionais discretas definidas segundo parâmetros de sexo, idade e local de moradia. Essa estratificação da amostra foi realizada em consultoria pela JLeiva Cultura \& Esporte, o que levou a um número amostral mínimo de 1.200 respondentes para a sua composição. $\mathrm{O}$ instrumento foi aplicado a pessoas com idades acima de 14 anos de diferentes grupos socioeconômicos em 19 áreas de grande circulação, como shopping centers, parques, praças públicas, calçadões públicos e lonas culturais dentro da definida zona de influência do Museu da Vida, no período entre novembro de 2017 e abril de 2018.

O questionário, além de coletar informações sobre o perfil sociodemográfico dos respondentes, perguntava qual era sua relação com ciência e tecnologia e se já haviam visitado o Museu da Vida, de modo a perscrutar seus interesses, hábitos e percepções sobre o campo científico. As perguntas foram elaboradas utilizando múltiplas escolhas ou escalas do tipo Likert, dependendo do caso. Os questionários foram tabulados utilizando a plataforma FormSUS do DataSus / Ministério da Saúde e foram analisados pelo software STATA. O projeto foi submetido ao Comitê de Ética em Pesquisa, registrado no Certificado de Apresentação para Apreciação Ética (CAAE) 75433317.3.0000.5241 e o parecer emitido foi que o projeto era isento de 
apreciação pelo comitê segundo o artigo 1 da resolução CNS/CONEP 510/2016 por se tratar de uma pesquisa de opinião com participantes não identificados.

Para as análises estatísticas, foram utilizados métodos paramétricos e não paramétricos para análise das distribuições (média, mediana, dispersão, histogramas, etc.) e métodos de inferência estatística para análise das correlações (testes-t e teste de $\chi^{2}$ de Pearson). Os cálculos de valor-p indicam a probabilidade de as variáveis serem correlacionadas ou não, mas não dizem nada sobre o efeito de uma sobre outra. Para isso, além dos cálculos da probabilidade de correlação (valores-p), foi calculado também o tamanho do efeito para análises que se mostraram correlacionadas, de forma a entender qual a força ou intensidade dessas relações. Para os testes de $\chi^{2}$, foi calculado o valor de V de Cramer e para os testes-t, a correlação ponto-bisserial. Esses testes estatísticos foram definidos de forma a manter a comparabilidade com situações internacionais segundo o trabalho de Falk e outros (2016). Segundo esse trabalho, valores de $\mathrm{V}$ de Cramer de $0,10,0,30$ e 0,50 e correlações pontobisseriais de 0,10,0,24 e 0,37 são considerados pequenos, médios e grandes, respectivamente. Para a realização das análises estatísticas, os respondentes foram separados em duas categorias: visitantes, aqueles que marcaram que já haviam visitado o Museu da Vida, e não visitantes, aqueles que selecionaram que não o haviam visitado ou não sabiam se o haviam visitado ou não.

\section{Análise dos resultados}

Para definir o universo de pesquisa e delinear o que é chamado de comunidade local na pesquisa internacional realizada por Falk e colaboradores (2016), foi necessário especificar o que seria a zona de influência do Museu da Vida. Na pesquisa internacional essa comunidade variou do bairro em que o equipamento se situa ao país como um todo. O Museu da Vida, situado na Zona Norte da cidade do Rio de Janeiro, está inserido dentro das contradições sociourbanas dessa cidade, que se caracteriza pela expansão desordenada de seu tecido urbano recortado por um relevo acentuado e em cuja própria geografia a desigualdade social se expressa. 
Com base no levantamento dos bairros de procedência dos visitantes espontâneos do Museu da Vida realizado em 2013 pelo Observatório de Museus e Centros de Ciência e Tecnologia (MANO et al., 2015), podemos definir que a sua zona de influência, seu território expandido, é composta pela AP1 (Região Central), pela AP2.2 (Grande Tijuca), pela AP3 (Zona Norte) e pela AP4.1 (Grande Jacarepaguá). Essa região engloba $56 \%$ da população carioca, no total compreendendo cerca de 3.020 .378 pessoas, $87,4 \%$ das quais com renda inferior a três salários mínimos. É uma região que se estende ao longo de algumas das principais vias expressas da cidade que passam próximas ao campus da Fiocruz em Manguinhos. Trata-se de uma região de população predominantemente de classe baixa ou média baixa, que abriga alguns dos maiores complexos de favelas do Rio de Janeiro (como o Complexo da Maré, o Complexo de Manguinhos, o Complexo do Alemão, o Complexo do Jacaré-Jacarezinho e a Cidade de Deus) e os bairros com os seis menores Índices de Desenvolvimento Humano (IDH) da cidade. Essa área concentra 79\% do público espontâneo carioca do Museu da Vida e 39\% do seu público total.

Figura 1 - Regiões de Planejamento que conformam a zona de influência do Museu da Vida em cor, com o Museu da Vida em destaque com a estrela vermelha

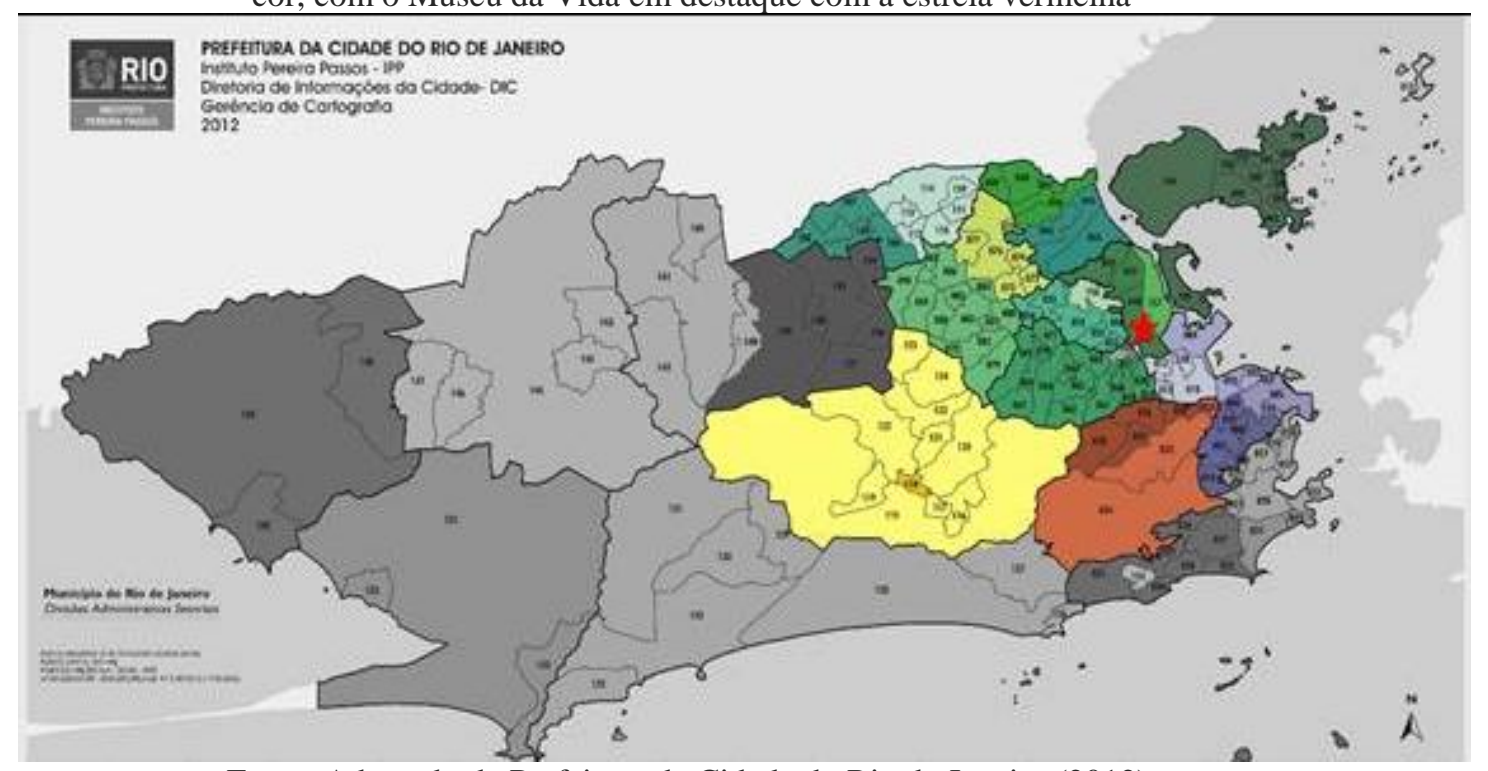

Fonte: Adaptado de Prefeitura da Cidade do Rio de Janeiro (2012).

Para o estudo do público visitante, foi realizado um inquérito em pontos específicos dessa zona de influência, conforme metodologia destacada anteriormente. Ao final da coleta, foram reunidos 1.496 questionários, dos quais 
1.296 foram validados, com erro amostral de 2,8\%. A amostra do estudo constituiu-se de $55 \%$ de mulheres e $45 \%$ de homens, com escolaridade majoritariamente até o Ensino Médio e 50\% com renda informada de até três salários mínimos. Os resultados obtidos a partir dos questionários formam um banco de dados muito importante sobre o papel do Museu da Vida para esse grande território que engloba as zonas Norte, Central e Grande Jacarepaguá do Rio de Janeiro. A partir desses dados, diferentes tipos de análises podem ser realizados em relação ao perfil desse público, ao impacto segundo os indicadores definidos, às características do público que nunca veio (entendido como público potencial).

Nesse território, $45,5 \%$ dos participantes da pesquisa já ouviram falar do Museu da Vida, 47,2\% afirmaram nunca ter ouvido nada a respeito e 7,3\% não responderam. Isso demonstra que, apesar de o Museu da Vida já estar aberto ao público há mais de 20 anos, ainda há um grande contingente da população que vive próxima ao Museu que ainda desconhece sua existência. Nesta mesma população cerca de 12,7\% visitaram o Museu da Vida pelo menos uma vez, enquanto cerca de $84,7 \%$ declararam nunca ter visitado o museu e $2,6 \%$ não lembravam ou não responderam. Considerando o total da população próxima pesquisada (1296), 32,6\% (422) já ouviu falar do Museu da Vida, contudo, nunca visitou o espaço. Isso mostra um grande potencial de público ainda a ser conquistado, buscando-se entender os motivos pelos quais essa parcela da população nunca fez uma visita a essa instituição pública e gratuita.

Daqueles que visitaram o museu, uma parcela considerável o fez recentemente. A pesquisa apontou que $42,7 \%$ daqueles que visitaram o Museu da Vida tinham ido lá no ano anterior. Ressalta-se ainda que muitos visitantes, mesmo das regiões próximas, eram visitantes de primeira vez.

Na Tabela 1 estão apresentados os dados sociodemográficos sobre visitantes e não visitantes do Museu da Vida na região considerada. Observa-se que os dados estão fornecidos em percentuais, exceto na primeira linha, onde estão representados valores absolutos, e na linha da idade, onde aparecem as médias das idades. A metodologia empregada nas análises segue a descrita por Falk e outros (2016). O valor de p representa a probabilidade de que a diferença 
encontrada entre as distribuições não seja verdadeira, ou seja, a partir de uma hipótese nula de igualdade entre as distribuições, um valor de $p$ consideravelmente pequeno (menor do que 0,05 ou $5 \%$, no nosso caso), rejeitaria essa hipótese, sugerindo que existe uma diferença estatisticamente significativa entre as distribuições. Como o valor de $\mathrm{p}$ apenas indica a probabilidade de as distribuições serem diferentes, ainda calculamos o tamanho do efeito para os casos que se mostraram significativos a partir do valor de $p$.

Tabela 1 - Perfil sociodemográfico dos respondentes da pesquisa divididos entre visitantes e não visitantes

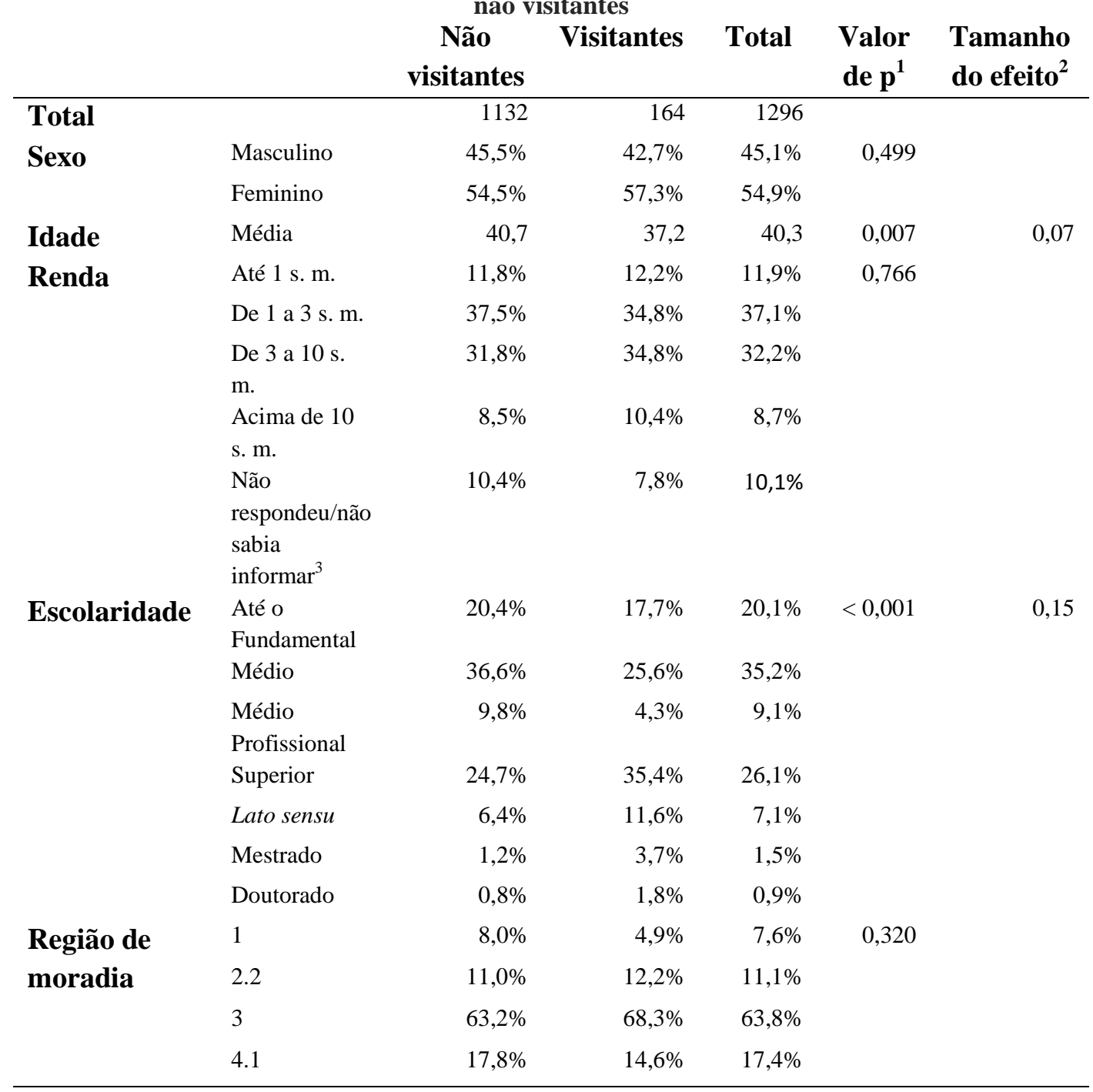

Fonte: Elaborado pelos autores.

$$
\text { Notas: }
$$

${ }^{1}$ Os valores de $\mathrm{p}$ foram calculados pelo teste de $\chi^{2}$ de Pearson, exceto o valor para idade, que foi calculado pelo teste-t.

${ }^{2} \mathrm{O}$ efeito de tamanho foi calculado por meio do $\mathrm{V}$ de Cramer para os testes de $\chi^{2}$ e a correlação pontobisserial para o teste-t. $\mathrm{O}$ tamanho do efeito apenas foi exibido para casos em que $\mathrm{p}<0,05$.

${ }^{3}$ A categoria Não respondeu / Não sabia informar não foi considerada para fins do cálculo do valor de 
De acordo com os resultados, a proporção de mulheres é ligeiramente maior entre o público do Museu da Vida (57,3\%) do que na amostra total $(54,9 \%)$ ou do que no grupo dos não visitantes $(54,5 \%)$. Este resultado está de acordo com o que já havia sido apontado pelas pesquisas anteriores (MANO et al., 2015). Essa diferença na proporção de homens e mulheres no grupo dos visitantes não é estatisticamente significativa $(\mathrm{p}>0,05)$, sendo equivalente à predominância demográfica das mulheres na própria região. Esse é um comportamento também presente na pesquisa conduzida por Falk e colaboradores (2016), porém que contrasta com o encontrado na pesquisa conduzida por Leiva e Meirelles (2018), que mostra uma predominância do público masculino na frequência a museus, sem ser, porém, um resultado conclusivo. No entanto, nessa mesma pesquisa, Leiva e Meirelles (2018) apontam que a frequência feminina em museus aumenta para mulheres com filhos.

Em relação à idade, obtivemos resultados divergentes dessa variável em relação às pesquisas internacionais (FALK et al., 2016). Se nelas não existe uma tendência em relação à idade dos frequentadores de centros e museus de ciência, o mesmo não acontece em relação ao Museu da Vida. O visitante do museu é em média três anos mais jovem do que a população analisada. Esta diferença, embora leve, é estatisticamente significativa. Por outro lado, em pesquisa realizada nacionalmente, Leiva e Meirelles (2018) encontraram que 50\% do público frequentador de museus no Brasil tem até 34 anos. Nessa presente pesquisa foi encontrado um valor de 36 anos para a mediana das idades, revelando apenas uma discreta diferença entre esses dois valores.

Um dos resultados que podemos observar na pesquisa de Falk e outros (2016) é que tanto a renda quanto a escolaridade são fatores preditivos da frequência ou não a centros e museus de ciência. Em ambos os casos, eles encontraram resultados estatisticamente positivos para rendas e escolaridades superiores. Na pesquisa de JLeiva Cultura \& Esporte (2016), é mostrado que o público de museus na cidade do Rio de Janeiro é um público majoritariamente branco, de maior renda, com ensino superior e morador da Zona Sul ou do centro. Entretanto, o público que afirmou ter visitado o Museu da Vida nesta 
pesquisa apresentou um perfil bastante diferente no que diz respeito a essas características. Trata-se de um público que provém predominantemente da Zona Norte do Rio de Janeiro que, como observado na Tabela 1, está bem distribuído nas diferentes faixas de renda e que não se distingue estatisticamente $(p>0,05)$ da população da região considerada. Do ponto de vista da escolaridade, porém, podemos perceber uma prevalência de pessoas com mais anos de estudo.

O Museu da Vida, mesmo alcançando uma população de menor renda, ainda assim atrai, nessa população, os grupos com maior escolaridade. Esse comportamento do público em relação às atividades culturais e de divulgação científica é observado também por outros autores. Aproveitando-se a noção de capital científico (ARCHER et al., 2015), pode-se dizer que a população que tem acesso a equipamentos culturais ligados à cultura científica busca, mesmo quando se trata de populações de baixa renda, novas experiências dentro desse campo. Leiva e Meirelles (2018) observam esse comportamento em sua pesquisa e afirmam que "[...] o efeito da educação é, em média, duas vezes maior que o da renda." (LEIVA; MEIRELLES, 2018, p. 54) em termos de acesso a atividades culturais. Nas pesquisas de Falk e colegas (2016), apesar de ambos os fatores prevalecerem, o tamanho do efeito da escolaridade é cerca de $50 \%$ maior que o da renda, o que corrobora os resultados obtidos nesta pesquisa.

Por meio de uma das questões colocadas aos respondentes, pretendeu-se investigar os hábitos de busca por informações ligadas à ciência e tecnologia durante a infância (até os 12 anos). Foi perguntado aos participantes com qual frequência realizavam as seguintes atividades: ler livros, revistas ou artigos de jornais sobre tópicos relacionados à ciência e tecnologia; usar a internet para pesquisar ou aprender sobre assuntos relacionados à ciência e tecnologia; assistir a programas educacionais na TV, a vídeos relacionados à ciência e tecnologia; ouvir podcasts ou programas de rádio relacionados à ciência e tecnologia; visitar museus relacionados à ciência e tecnologia ou aquários, jardins zoológicos, jardins botânicos, planetários; participar de clubes ou grupos relacionados à ciência e tecnologia ou desenvolver individualmente atividades relacionadas à ciência e tecnologia (tais como astronomia amadora, aeromodelismo, programação, trilhas ecológicas, cultivo de plantas e criação de animais) e 
conversar sobre tópicos de ciência e tecnologia com amigos ou família. $\mathrm{Na}$ escala de frequência apresentada, um (1) correspondia a "diariamente"; dois (2), a "semanalmente" e seis (6), a "nunca". Portanto, no cálculo das médias, que variaram de um a seis, quanto menor o valor obtido, maior seria a frequência de realização das atividades de busca por informação ligadas à ciência e tecnologia (C\&T), o que indicaria a existência de hábitos e, possivelmente, um maior interesse, conforme pode ser observado na Tabela 2.

Tabela 2 - Valores das médias das escalas, valor de p e tamanho de efeito para as atividades de busca por informação ligada à ciência e tecnologia $(C \& T)$ na infância.

\begin{tabular}{lcccc} 
Atividade & Visitantes & $\begin{array}{c}\text { Não } \\
\text { visitantes }\end{array}$ & $\begin{array}{c}\text { Valor de } \\
\mathbf{p}^{\mathbf{4}}\end{array}$ & $\begin{array}{c}\text { Tamanho } \\
\text { do efeito }^{\mathbf{5}}\end{array}$ \\
\hline Ler livros, jornais e & 3,5 & 3,8 & 0,005 & 0,11
\end{tabular}

revistas

$\begin{array}{llll}\text { Usar a internet para } & 5 & 5,1 & 0,238\end{array}$

pesquisar

$\begin{array}{llll}\text { Assistir a programas na } & 3,5 & 3,8 & 0,187\end{array}$

TV ou ouvir programas

de rádio

Visitar museu de C\&T,

$<0,001$

0,15

jardins zoológicos,

jardins botânicos,

aquários e planetários

Participar de clubes de

0,106

ciência

Conversar com amigos

4,3

4,7

0,106

Fonte: Elaborado pelos autores.

Notas:

${ }^{4}$ Os valores de $\mathrm{p}$ foram calculados pelo teste de $\chi^{2}$ de Pearson, utilizando a frequência de resposta de cada pergunta ao longo da escala.

${ }^{5} \mathrm{O}$ efeito de tamanho foi calculado por meio do $\mathrm{V}$ de Cramer.

Destacam-se na Tabela 2 os altos valores (ou seja, baixa frequência) declarados para o uso da internet como meio para pesquisa de assuntos ligados à ciência e tecnologia. Como a pergunta se referia aos hábitos de infância e os respondentes tinham idades muito variadas, provavelmente a maior parte deles 
não tinha acesso à internet quando tinha idade inferior a 12 anos, o que explicaria essa baixa frequência.

A Tabela 2 apresenta resultados estatísticos positivos para uma predominância dos hábitos de leitura de livros, jornais e revistas ligados à ciência e tecnologia e de visitação de espaços não formais de ciência entre aqueles que visitaram o Museu da Vida. Conforme estabelecido por Archer e colaboradores (2015), esses são hábitos culturais que fazem parte do capital científico desse público. Tais hábitos, quanto praticados em família - em particular durante a infância - influenciam fortemente as escolhas e percepções sobre ciência na fase adulta. Cabe, porém, notar que em todos os casos, as diferenças são muito pequenas - muitas vezes marginais - no tamanho do efeito, como pode ser observado na própria diferença entre as médias das escalas apresentadas.

Em relação à população que visitou o Museu da Vida, perguntou-se o quanto, em sua percepção, a visita ao Museu influenciou: o seu interesse por ciência e tecnologia, o seu conhecimento sobre ciência e tecnologia e a sua participação em atividades que envolvam ciência e tecnologia. As possíveis respostas eram: muito; moderadamente; um pouco e nada. Na Figura 2 podemos observar as respostas daqueles que visitaram o Museu da Vida.

Figura 2 - Gráfico com o percentual de respostas do público visitante relativo à contribuição da visita ao Museu da Vida para seu interesse, conhecimento e engajamento em atividades de C\&T

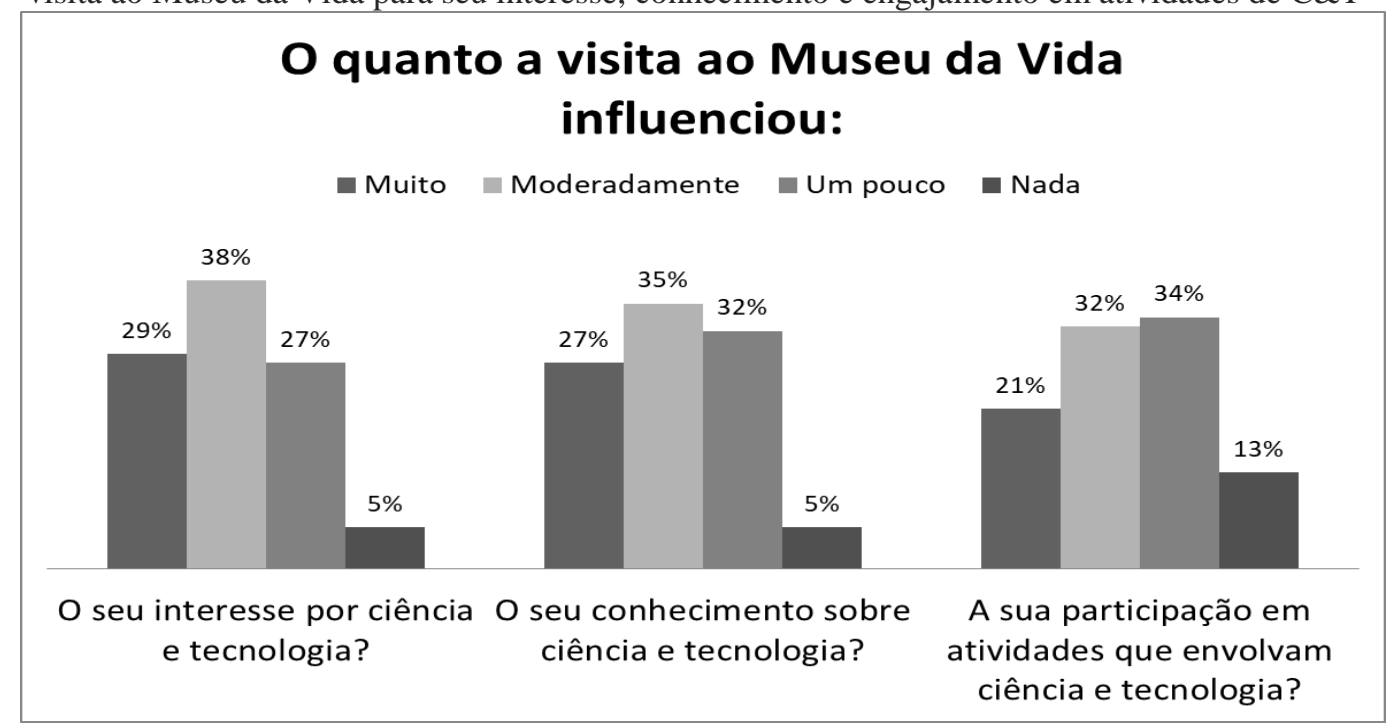

Fonte: Elaborado pelos autores. 
No seu plano museológico, a missão do museu está definida como: "Despertar o interesse e promover o diálogo público em ciência, tecnologia e saúde, e seus processos históricos, visando à promoção da cidadania e à melhoria da qualidade de vida." (FUNDAÇÃO OSWALDO CRUZ, 2017, p. 22). Como observado na Figura 2, as perspectivas de informar sobre ciência e tecnologia e de promover o interesse aparecem como as dimensões mais percebidas pelo público, na medida em que $67 \%$ do público visitante afirmou que a visita ao museu influenciou muito ou moderadamente seus conhecimentos ou seu interesse $(62 \%)$ sobre ciência e tecnologia. Por outro lado, a perspectiva de promover a participação ou o engajamento do público em atividades de ciência e tecnologia ainda é pouco percebida pelos mesmos visitantes, pois apenas $53 \%$ destes afirmaram que a visita aumentou moderadamente ou muito sua participação em atividades correlatas. Este resultado sugere que, embora seja um propósito do Museu da Vida promover a cidadania e o engajamento dos seus visitantes, ainda há uma baixa percepção pelo público quanto a capacidade de suas atividades estimularem essa dimensão, sendo mais favorecidas as duas primeiras dimensões apontadas.

Por fim, é importante observar que o grupo dos visitantes do Museu da Vida revelou uma maior habilidade em discernir e explicar certos resultados da pesquisa científica que estão sob ataque de correntes anticientíficas e de fake news. Uma das questões sondava a facilidade dos respondentes para: explicar por que as vacinas são importantes para a prevenção de doenças; prever como mudanças num ambiente afetarão a sobrevivência de algumas espécies; discutir como o desmatamento pode influenciar o clima e a disponibilidade de água potável; explicar como ocorre a transmissão de doenças por insetos, como, por exemplo, dengue, zika, doença de Chagas, dentre outras, e quais são as medidas para prevenir sua disseminação e discutir os efeitos dos agrotóxicos sobre o meio ambiente e sobre a saúde humana. As respostas foram dadas a partir de uma escala na qual um (1) representava nenhuma, dois (2) pouca, três (3) moderada e quatro (4) muita facilidade. Assim, quanto mais elevadas as médias obtidas, maior a facilidade percebida pelo respondente em explicar, discutir e compreender os temas indicados. Os resultados das médias para os visitantes e 
não visitantes, o valor de p para identificar se há uma diferença significativa entre as médias das populações e o seu tamanho de efeito estão representados na Tabela 3.

Tabela 3 - Médias das escalas, valor de p e tamanho de efeito das respostas de visitantes e não visitantes quanto a sua facilidade em estabelecer certas relações

\begin{tabular}{lcccc} 
Relações & Visitantes & Não visitantes & Valor de $^{\mathbf{6}}$ & $\begin{array}{c}\text { Tamanho do } \\
\text { efeito }^{7}\end{array}$ \\
\hline $\begin{array}{l}\text { Vacinas e prevenção } \\
\text { de doenças } \\
\text { Ambiente e } \\
\text { sobrevivência de }\end{array}$ & 3,4 & 3 & $<0,001$ & 0,14 \\
$\begin{array}{l}\text { espécies } \\
\text { Desmatamento, clima }\end{array}$ & 3,2 & 2,8 & $<0,001$ & 0,16 \\
$\begin{array}{l}\text { e água potável } \\
\text { Insetos e arboviroses }\end{array}$ & 3,2 & 2,9 & $<0,001$ & 0,12 \\
$\begin{array}{l}\text { Agrotóxicos, meio } \\
\text { ambiente e saúde } \\
\text { humana }\end{array}$ & 2,9 & 2,9 & $<0,001$ & 0,15 \\
\hline
\end{tabular}

Fonte: Elaborado pelos autores.

Notas:

${ }^{6}$ Os valores de $\mathrm{p}$ foram calculados pelo teste de $\chi^{2}$ de Pearson, utilizando a frequência de resposta de cada pergunta ao longo da escala.

${ }^{7} \mathrm{O}$ efeito de tamanho foi calculado por meio do $\mathrm{V}$ de Cramer.

Podemos observar na Tabela 3 que, para todos os itens analisados, existe uma diferença estatisticamente significativa entre as médias das respostas dos que haviam visitado o Museu da Vida e daqueles que não o haviam visitado. Em todos os casos, o tamanho do efeito é superior ao mínimo, levando a considerar que se trata de uma correlação real. A participação e o engajamento em atividades de divulgação e popularização da ciência são frequentemente vistos como uma ferramenta importante de enfrentamento ao anticientificismo e às fake news em ciência. Castelfranchi (2018), em seu artigo de divulgação científica, argumenta que o engajamento no processo científico é muito mais eficaz na rejeição da notícia falsa que esse acesso à informação isolado. Dessa forma, um museu de ciência, como um ambiente de discussão e debate sobre ciência e tecnologia, parece ser um local de grande importância na reversão de um quadro crescente de desconfiança em relação à ciência. 


\section{Conclusões}

Este trabalho é fruto de um acúmulo de diferentes pesquisas com instrumentos e protocolos compartilhados por este grupo com o objetivo de entender melhor o público do Museu da Vida e o impacto de suas ações nos seus visitantes. Neste sentido, a definição da zona de influência do Museu da Vida permitiu entender a procedência de nossos visitantes e de nosso público em potencial e seus perfis e interesses por meio de dados sociodemográficos. Essa caracterização do público é fundamental para compreender melhor os impactos e indicadores de atuação de um equipamento cultural como o Museu da Vida e para produzir conhecimentos sobre esses impactos e indicadores de atuação, mas também para guiar de forma criteriosa uma avaliação das suas ações e o delineamento de novas práticas. Segundo os resultados deste estudo, foi possível observar que esse público visitante é razoavelmente bem distribuído dentro da zona de influência (Zona Central, Grande Tijuca, Zona Norte, Grande Jacarepaguá), com aparente concentração na Zona Norte, área mais próxima ao Museu da Vida. Trata-se de um público relativamente jovem, mais novo que os não visitantes, com faixas de renda bem distribuídas dentro da demografia da região, com um padrão de escolaridade maior que a média local. Por outro lado, esse público é interessado em ciência e tecnologia e influenciado pelos hábitos familiares e adquiridos na infância, dentre os quais o hábito de visitar espaços de educação não formal em ciência se destaca como relevante.

Vimos que o público do Museu da Vida percebe e avalia bem a missão da instituição de despertar o interesse em ciência e tecnologia. Ainda foi possível perceber que esse mesmo público parece se sentir capaz de compreender com maior facilidade temas científicos relevantes para a sociedade contemporânea, mesmo aqueles sobre os quais notícias falsas têm sido amplamente difundidas em movimentos anticientíficos. Dessa forma, reafirmamos o papel do museu de ciência de ser um espaço de diálogo da ciência com a população e um instrumento para promover a cidadania e um maior engajamento da sociedade no debate científico e tecnológico. Nessa relação dialética entre ação e reflexão, buscou-se compreender melhor o processo de dicotomia entre exclusão e protagonismo cultural existente na 
região, questão que vem guiando as diretrizes dessa instituição desde sua abertura, movida pelos princípios de exercício de cidadania e de democratização do acesso à cultura.

\section{Financiamento}

Esse trabalho contou com financiamento do Conselho Nacional de Desenvolvimento Científico e Tecnológico e da Casa de Oswaldo Cruz por meio da Chamada CNPq/FIOCRUZ/COC/ No. 3/2015.

\section{Agradecimentos}

Os autores gostariam de agradecer as seguintes instituições por autorizar a pesquisa em suas dependências: Administração do Parque de Madureira; Shopping Nova América; Administração do Bosque do Grajaú, Subsecretaria Municipal de Meio Ambiente; Associação Comercial do Largo da Freguesia; Administração do Bosque da Freguesia, Center Shopping de Jacarepaguá, Shopping Main Street, Carioca Shopping; Lona Cultural de Madureira; e INPAR.

Por fim, os autores dedicam esse trabalho in memoriam a Loloano Claudionor da Silva, jovem pesquisador, coautor desse trabalho, apaixonado por divulgação científica, que infelizmente nos deixou antes da conclusão desse artigo.

\section{Referências}

ALMEIDA, A. M. O contexto do visitante na experiência museal: semelhanças e diferenças entre museus de ciência e de arte. História, Ciência, Saúde Manguinhos, Rio de Janeiro, v. 12, p. 31-53, 2005.

ARCHER, L. et al. "Science Capital": a conceptual, methodological, and empirical argument for extending Bourdieusian notions of capital beyond the arts. Journal of Research in Science Teaching, Champaign, v. 52, n. 7, p. 922948, 2015.

BOURDIEU, P. Forms of capital. In J. Richardson (Ed.), Handbook of theory and research for the sociology of education, New York: Greenwood, 1986, p. 241-258 
CASTELFRANCHI, Y. Notícias falsas em ciência. Ciência Hoje, Rio de Janeiro, n. 350, p. 16-22, 2018.

DAWSON, E. "Not designed for us": how science museums and science centers socially exclude low-income, minority ethnic groups. Science Education, [s.1.], v. 98, n. 6, p. 981-1113, 2014.

FALK, J. H.; DIERKING, L. D. The 95 percent solution: school is not where most Americans learn most of their science. American Scientist, Research Triangle Park, v. 48, n. 6, p. 486-493, 2010.

FALK, J. H.; DIERKING, L. D. The museum experience revisited. Walnut Creek: Left Coast Press, 2013.

FALK, J. H. et al. Correlating science center use with adult science literacy: an international, cross-institutional study. Science Education, [s.1.], v. 100, n. 5, p. 849-876, 2016.

FALK, J. H.; STORKSDIECK, M. Learning science from museums. História, Ciências, Saúde - Manguinhos, Rio de Janeiro, v. 12, p. 117-143, 2005.

FUNDAÇÃO OSWALDO CRUZ. Museu da Vida. Plano Museológico Museu da Vida 2017-2021. Rio de Janeiro: Casa de Oswaldo Cruz, 2017.

HARVARD FAMILY RESEARCH PROJECT. Findings from HFRP's study of predictors of participation in out-of-school time activities: fact sheet. Cambridge, Massachusetts: Harvard Graduate School of Education, 2007. Disponível em: https://archive.globalfrp.org/content/download/1072/48575/file/ findings_predictor_OSOSTfactshe.pdf. Acesso em: 22 maio 2019.

HEIN, G. Learning in the museum. Londres: Routledge, 1998.

HOOD, M. G. After 70 years of audience research, what have we learned? who comes to museum, who does not, and why? In: Benefield, A.; Bitgood, S.; Shettel, H.; Williams, R.; Thompson, D. (ed.). Visitors Studies, theory, research and practice. Collected Papers From The 1992 Visitor Studies Conference, Volume 5. Jacksonville: The Visitors Studies Association, 1993, p. $16-27$.

JLEIVA CULTURA E ESPORTE. Seminário perfil cultural dos cariocas. [Rio de Janeiro], 2016. Disponível em: http://www.culturanorio.com.br. Acesso em: 17 jun. 2019.

LARAIA, R. B. Cultura: um conceito antropológico. Rio de Janeiro: Zahar, 1986. 
LEIVA, J.; MEIRELLES, R. Cultura nas capitais: como 33 milhões de brasileiros consomem diversão e arte. Rio de Janeiro: 17Street Produção Editorial, 2018.

MANO, S. M. F. et al. O público do Museu da Vida (1999 a 2013). Rio de Janeiro: Museu da Vida, 2015.

PREFEITURA DA CIDADE DO RIO DE JANEIRO. Instituto Pereira Passos. Município do Rio de Janeiro: divisões administrativas setoriais. Rio de Janeiro: [s. n.], 2012. Disponível em: http://www.rio.rj.gov.br/dlstatic/10112/ 5148142/4145881/ListadeBairroseAPs_Mapa.pdf. Acesso em: 25 jun. 2019.

SCHEINER, T. C. Repensando o museu integral: do conceito às práticas. Ciências Humanas, Belém, v. 7, n. 1, p. 15-30, 2012.

TRAUTMANN, C. et al. Reaching new audiences at science centers and museums. Informal Learning Review, Denver, n. 149, p. 13-19, 2018.

\title{
Rio de Janeiro's Museu da Vida and its publics: reflections on influence zone and the social role of a science museum
}

\begin{abstract}
In this paper we set out to define the zone of influence of Rio de Janeiro's Museu da Vida ("Museum of Life"), that is, the areas of that municipality where most of its visitors come from and whose population would be the basis for the survey sampling. We are thus able to make a sociodemographic analysis of this public and to point out its relevant characteristics. This definition of the zone of influence within the city brought together concepts of territory and the accumulated knowledge about where the visitors to Museu da Vida come from. Such zone was defined as a continuous area of Rio de Janeiro covering the Zona Central, Grande Tijuca, Zona Norte and Grande Jacarepaguá. In this area, 1296 people answered a questionnaire, of which $13 \%$ had already visited Museu da Vida. In contrast to those who had never visited the museum, the audience that had already done so was relatively young. We found that there was a discrete majority of women and that the income was well distributed compared with that of the local sociodemographics, but the level of education was higher than average. By means of that survey, we also sought to look into cultural habits related to the search for information on science and technology during childhood; into the visitors' perception about the influence of their visit to the museum; into their interest in, knowledge of and engagement with science and technology topics and into the way they deal with fake news in science. This work allowed us to take a more systemic view on the role of a science museum in a region with a very low supply of science and culture equipment.
\end{abstract}


Keywords: Visitor studies. Science communications. Science museum. Zone of influence. Museu da Vida.

Recebido: 26/09/2019

Aceito: 10/12/2019

${ }^{1}$ LEVY JUNIOR, M. J. The structure of society. Princeton: Princeton University Press, 1952. Apud Laraia (1986). 